\title{
Approximation of Fixed Points and Best Proximity Points of Relatively Nonexpansive Mappings
}

\author{
Thabet Abdeljawad $\mathbb{D}^{1,2,3}$ Kifayat Ullah, ${ }^{4}$ Junaid Ahmad $\mathbb{D}^{4},{ }^{4}$ Manuel De La Sen $\left(\mathbb{D},{ }^{5}\right.$ \\ and Azhar Ulhaq ${ }^{4}$ \\ ${ }^{1}$ Department of Mathematics and General Sciences, Prince Sultan University, P.O.Box 66833, Riyadh 11586, Saudi Arabia \\ ${ }^{2}$ Department of Medical Research, China Medical University, Taichung 40402, Taiwan \\ ${ }^{3}$ Department of Computer Sciences and Information Engineering, Asia University, Taichung, Taiwan \\ ${ }^{4}$ Department of Mathematics, University of Science and Technology, Bannu 28100, Khyber Pakhtunkhwa, Pakistan \\ ${ }^{5}$ Institute of Research and Development of Processes, University of the Basque Country, Campus of Leioa (Bizkaia), \\ P.O. Box 644- Bilbao, Barrio Sarriena, 48940 Leioa, Spain
}

Correspondence should be addressed to Junaid Ahmad; ahmadjunaid436@gmail.com

Received 31 August 2020; Revised 9 September 2020; Accepted 16 September 2020; Published 29 October 2020

Academic Editor: Hijaz Ahmad

Copyright (c) 2020 Thabet Abdeljawad et al. This is an open access article distributed under the Creative Commons Attribution License, which permits unrestricted use, distribution, and reproduction in any medium, provided the original work is properly cited.

In this article, we study the Agarwal iterative process for finding fixed points and best proximity points of relatively nonexpansive mappings. Using the Von Neumann sequence, we establish the convergence result in a Hilbert space framework. We present a new example of relatively nonexpansive mapping and prove that its Agarwal iterative process is more efficient than the Mann and Ishikawa iterative processes.

\section{Introduction}

Let $E$ be a nonempty subset of a Banach space $X$. A self-map $T$ of $E$ is said to be nonexpansive mapping if

$$
\|T u-T v\| \leq\|u-v\|, \quad \text { for all } u, v \in E .
$$

The class of nonexpansive mappings is important as an application point of view. One of the celebrated result of Kirk [1] states that any self nonexpansive mapping of closed bounded convex subset $E$ of a reflexive Banach space has a fixed point provided that $E$ has normal structure. This result was also independently proved in the same year by Browder [2] and Gohde [3] in uniformly convex Banach space (in short UCBS). After this celebrated result, many generalizations of nonexpansive mappings have been published [4-14]. Among the other things, one of the natural generalization of nonexpansive mappings was given by Eldred et al. [15] as follows. Let $H$ and $L$ be two nonempty subsets of a Banach space $X$. A self-map $T$ of $H \cup L$ is said to be relatively nonexpansive if

$$
\|T u-T v\| \leq\|u-v\|, \quad \text { for all } u \in H \text { and } v \in L .
$$

Iterative methods played a very important role in variational inequalities and many other areas of applied sciences (e.g., see [16-27] and others). One of the earlier iterative scheme is the Picard iteration process, $u_{n+1}=T u_{n}$, which converges very well for Banach contraction mappings. However, this scheme is not suitable for finding fixed points of nonexpansive mappings and hence for the generalized nonexpansive mappings. Let $E$ be a nonempty subset set of a Banach space X. In [30], Eldred and Praveen studied Mann [29] iterative process for finding fixed points and best proximity points of relatively nonexpansive mappings. In [30], Gopi and Pragadeeswara studied Ishikawa [31] iterative process for finding fixed points and best proximity points of relatively nonexpansive mappings.

Motivated by the above work, we study the Agarwal [32] iterative process for finding fixed points and best proximity points of relatively nonexpansive mappings. We present a new example of relatively nonexansive mapping and prove 
that its Agarwal iterative process is more efficient than the Mann [29] and Ishikawa [31] iterative processes.

Now, we present some notations which will be used in the sequel:

$$
\begin{aligned}
P_{H}(u) & =\{v \in H:\|u-v\|=d(u, H)\}, \\
d(H, L) & =\inf \{\|u-v\|: u \in H, v \in L\}, \\
H_{0} & =\left\{u \in H:\left\|u-v^{\prime}\right\|=d(H, L) \text { for some } v^{\prime} \in L\right\}, \\
L_{0} & =\left\{v \in L:\left\|u^{\prime}-v\right\|=d(H, L) \text { for some } u^{\prime} \in H\right\} .
\end{aligned}
$$

Notice that $P_{H}(u)$ is singleton, provided that $H$ is closed convex in a reflexive and strictly convex space. Moreover, if $H$ and $L$ are a closed convex in a reflexive space, such that one of the $H$ and $L$ is bounded, then $H_{0} \neq \varnothing$.

A handful of definitions and theorems given below correspond to our results.

Definition 1. Suppose that $H$ and $L$ be two nonempty subsets of a metric space. A point $u \in H$ is said to be a best proximity point of the nonself-map $T: H \longrightarrow L$ provided that

$$
d(u, T u)=d(H, L)
$$

Theorem 1 (see [15]). Suppose $H$ and $L$ be two nonempty bounded closed convex subsets of a UCBS. Assume that $T: H \cup L \longrightarrow H \cup L$ satisfies

(i) $T(H) \subseteq L$ and $T(L) \subseteq H$

(ii) $\|T u-T v\| \leq\|u-v\|$ for all $u \in H, v \in L$

Then, there exist $(u, v) \in H \times L$ such that $\|u-T u\|=\| v-$ $T v \|=d(H, L)$.

Theorem 2 (see [15]). Suppose $H$ and $L$ be two nonempty closed bounded convex subsets of a UCBS. If $T: H \cup L \longrightarrow H \cup L$ satisfies the following:

(i) $T(H) \subseteq H$ and $T(L) \subseteq L$

(ii) $\|T u-T v\| \leq\|u-v\|$ for all $u \in H, v \in L$

Then, there exist $u_{0} \in H$ and $v_{0} \in L$ such that $T u_{0}=$ $u_{0}, T v_{0}=v_{0}$, and $\left\|u_{0}-v_{0}\right\|=d(H, L)$.

Theorem 3 (see [1-3]). Assume that $T$ be a self-map on a closed convex bounded subset of a UCBS. If T is nonexpansive, then $T$ has a fixed point.

Proposition 1 (see [33]). Suppose that $X$ is a UCBS, $\alpha \in(0,1)$ and $\varepsilon>0$, then for each $d>0$ and $u, v \in X$ be such that $\|u\| \leq d,\|v\| \leq d,\|u-v\| \geq \varepsilon$, then there exists some $\delta=$ $\delta(\varepsilon / d)>0$ such that $\|u+(1-\alpha) v\| \leq(1-2 \delta(\varepsilon / d)(\alpha, 1-$ $\alpha)) d$.

Lemma 1 (see [34]). Let $0<a<t_{n}<b<1$ for every $n \geq 1$. Assume that $\left\{u_{n}\right\}$ and $\left\{v_{n}\right\}$ are sequence in a UCBS $X$ such that $\left\|u_{n}\right\| \leq 1,\left\|v_{n}\right\| \leq 1$. Define $\left\{b_{n}\right\}$ in $X$ by $b_{n}=\left(1-t_{n}\right) u_{n}+t_{n} v_{n}$. If $\quad \lim _{n \longrightarrow \infty}\left\|b_{n}\right\|=1$, then $\lim _{n \rightarrow \infty}\left\|u_{n}-v_{n}\right\|=0$.

Now, we are going to show that, under some appropriate assumptions, Agarwal's [32] iteration converges to a fixed point of a given nonexpansive mapping. This result is useful for the upcoming main results.

Theorem 4. Suppose $E$ be a nonempty bounded closed convex subset of a UCBS $X$, and assume that $T$ be a self-map nonexpansive map of $E$. Choose $u_{0} \in E$ and set $v_{n}=\left(1-\beta_{n}\right) u_{n}+\beta_{n} T u_{n}, u_{n+1}=\left(1-\alpha_{n}\right) T u_{n}+\alpha_{n} T v_{n}$, where $\beta_{n}, \alpha_{n} \in(\varepsilon, 1-\varepsilon), n=0,1,2, \ldots$ and $\varepsilon \in(0,1 / 2)$ and $\sum \alpha_{n} \beta_{n}<\infty$. Then, $\lim _{n \rightarrow \infty}\left\|u_{n}-T u_{n}\right\|=0$. Moreover, if $T(E)$ lies in a compact set, then $\left\{u_{n}\right\}$ converges to a fixed point of $T$.

Proof. By Theorem 3, there exists some $v \in E$ such that $T v=v$. Now,

$$
\begin{aligned}
\left\|v_{n}-v\right\| & =\left\|\left(1-\beta_{n}\right) u_{n}+\beta_{n} T u_{n}-v\right\| \\
& \leq\left(1-\beta_{n}\right)\left\|u_{n}-v\right\|+\beta_{n}\left\|T u_{n}-v\right\| \\
& \leq\left(1-\beta_{n}\right)\left\|u_{n}-v\right\|+\beta_{n}\left\|u_{n}-v\right\| \\
& =\left\|u_{n}-v\right\|, \\
\left\|u_{n+1}-v\right\| & =\left\|\left(1-\alpha_{n}\right) T u_{n}+\alpha_{n} T v_{n}-v\right\| \\
& \leq\left(1-\alpha_{n}\right)\left\|T u_{n}-v\right\|+\alpha_{n}\left\|T v_{n}-v\right\| \\
& \leq\left(1-\alpha_{n}\right)\left\|u_{n}-v\right\|+\alpha_{n}\left\|v_{n}-v\right\| \\
& \leq\left(1-\alpha_{n}\right)\left\|u_{n}-v\right\|+\alpha_{n}\left\|u_{n}-v\right\| \\
& =\left\|u_{n}-v\right\| .
\end{aligned}
$$

It follows that the sequence $\left\{\left\|u_{n}-v\right\|\right\}$ is nonincreasing and bounded below by 0 . Hence, we have $\left\|u_{n}-v\right\| \longrightarrow d \geq 0$.

Case 1. If $\left\|u_{n}-v\right\| \longrightarrow 0$, then

$$
\begin{aligned}
\left\|u_{n}-T u_{n}\right\| & \leq\left\|u_{n}-v\right\|+\left\|v-T u_{n}\right\| \\
& =\left\|u_{n}-v\right\|+\left\|T v-T u_{n}\right\| \\
& \leq\left\|u_{n}-v\right\|+\left\|u_{n}-v\right\| .
\end{aligned}
$$

If $n \longrightarrow \infty$, then $\left\|u_{n}-T u_{n}\right\| \longrightarrow 0$. Now, 


$$
\begin{aligned}
\left\|u_{n+1}-u_{n}\right\| & =\left\|\left(1-\alpha_{n}\right) T u_{n}+\alpha_{n} T v_{n}-u_{n}\right\| \\
& =\left\|T u_{n}-\alpha_{n} T u_{n}+\alpha_{n} T v_{n}-u_{n}\right\| \\
& \leq \alpha_{n}\left\|T u_{n}-T v_{n}\right\|+\left\|T u_{n}-u_{n}\right\| \\
& \leq \alpha_{n}\left\|v_{n}-u_{n}\right\|+\left\|T u_{n}-u_{n}\right\| \\
& =\alpha_{n}\left\|\left(1-\beta_{n}\right) u_{n}+\beta_{n} T u_{n}-u_{n}\right\|+\left\|T u_{n}-u_{n}\right\| \\
& \leq \alpha_{n} \beta_{n}\left\|T u_{n}-u_{n}\right\|+\left\|T u_{n}-u_{n}\right\| \\
& =\left(\alpha_{n} \beta_{n}+1\right)\left\|T u_{n}-u_{n}\right\| \\
& \leq\left(\alpha_{n} \beta_{n}+1\right)\left(\left\|T u_{n}-v\right\|+\left\|v-u_{n}\right\|\right) \\
& =\left(\alpha_{n} \beta_{n}+1\right)\left(\left\|T u_{n}-T v\right\|+\left\|v-u_{n}\right\|\right) \\
& \leq\left(\alpha_{n} \beta_{n}+1\right)\left(\left\|u_{n}-v\right\|+\left\|v-u_{n}\right\|\right) .
\end{aligned}
$$

If $n \longrightarrow \infty$, then $\left\|u_{n+1}-u_{n}\right\| \longrightarrow 0$.

Case 2. If $\left\|u_{n}-v\right\| \longrightarrow d>0$, we need to show that $\left\|u_{n}-T u_{n}\right\| \longrightarrow 0$. Suppose not, then one have a subsequence $\left\{u_{n_{k}}\right\}$ of $\left\{u_{n}\right\}$ and a positive real number $\varepsilon$ such that $\left\|u_{n_{k}}-T u_{n_{k}}\right\| \geq \varepsilon>0$ for all $k$.

Since the modulus of convexity $\delta$ of $X$ is continuous as well as increasing function, one can select some $\xi>0$ as small such that $(1-c \delta(\varepsilon /(d+\xi)))(d+\xi)<d$, where $c>0$.

Now, we select $k$, such that $\left\|u_{n_{k}}-v\right\| \leq d+\xi$. By Proposition 1 , we have

$$
\begin{aligned}
\left\|v-u_{n_{k}+1}\right\|= & \left\|v-\left(\left(1-\alpha_{n_{k}}\right) T u_{n_{k}}+\alpha_{n_{k}} T v_{n_{k}}\right)\right\| \\
= & \left\|v-\left(\left(1-\alpha_{n_{k}}\right) T u_{n_{k}}+\alpha_{n_{k}} T\left(\left(1-\beta_{n_{k}}\right) u_{n_{k}}+\beta_{n_{k}} T u_{n_{k}}\right)\right)\right\| \\
= & \|\left(1-\alpha_{n_{k}}\right) v+\alpha_{n_{k}} v-\left(\left(1-\alpha_{n_{k}}\right) T u_{n_{k}}+\alpha_{n_{k}} T\left(\left(1-\beta_{n_{k}}\right) u_{n_{k}}\right.\right. \\
& \left.\left.+\beta_{n_{k}} T u_{n_{k}}\right)\right) \| \\
\leq & \left(1-\alpha_{n_{k}}\right)\left\|v-T u_{n_{k}}\right\|+\alpha_{n_{k}}\left\|v-T\left(\left(1-\beta_{n_{k}}\right) u_{n_{k}}+\beta_{n_{k}} T u_{n_{k}}\right)\right\| \\
= & \left(1-\alpha_{n_{k}}\right)\left\|T v-T u_{n_{k}}\right\|+\alpha_{n_{k}}\left\|T v-T\left(\left(1-\beta_{n_{k}}\right) u_{n_{k}}+\beta_{n_{k}} T u_{n_{k}}\right)\right\| \\
\leq & \left(1-\alpha_{n_{k}}\right)\left\|v-u_{n_{k}}\right\|+\alpha_{n_{k}}\left\|v-\left(\left(1-\beta_{n_{k}}\right) u_{n_{k}}+\beta_{n_{k}} T u_{n_{k}}\right)\right\| \\
= & \left(1-\alpha_{n_{k}}\right)(d+\xi)+\alpha_{n_{k}}\left\|\left(1-\beta_{n_{k}}\right)\left(v-u_{n_{k}}\right)+\beta_{n_{k}}\left(v-T u_{n_{k}}\right)\right\| \\
\leq & \left(1-\alpha_{n_{k}}\right)(d+\xi)+\alpha_{n_{k}}(1 \\
& \left.-2 \delta\left(\frac{\varepsilon}{d+\xi}\right) \min \left\{\beta_{n_{k}}, 1-\beta_{n_{k}}\right\}\right)(d+\xi) \\
= & \left(1-\alpha_{n_{k}}+\alpha_{n_{k}}-2 \alpha_{n_{k}} \delta\left(\frac{\varepsilon}{d+\xi}\right) \min \left\{\beta_{n_{k}}, 1-\beta_{n_{k}}\right\}\right)(d+\xi) \\
= & \left(1-2 \delta\left(\frac{\varepsilon}{d+\xi}\right) \min \left\{\alpha_{n_{k}} \beta_{n_{k_{k}}}, \alpha_{n_{k}}\left(1-\beta_{n_{k}}\right)\right\}\right)(d+\xi) .
\end{aligned}
$$

Since there exist $h>0$, such that $2 \min \left\{\alpha_{n_{k}} \beta_{n_{k}}, \alpha_{n_{k}}\left(1-\beta_{n_{k}}\right)\right\} \geq h$,

$$
\begin{aligned}
(1 & \left.-2 \delta\left(\frac{\varepsilon}{d+\xi}\right) \min \left\{\alpha_{n_{k}} \beta_{n_{k}}, \alpha_{n_{k}}\left(1-\beta_{n_{k}}\right)\right\}\right)(d+\xi) \\
\leq & \left(1-h \delta\left(\frac{\varepsilon}{d+\xi}\right)\right)(d+\xi) .
\end{aligned}
$$

Select very small $\xi>0$, we have $(1-h \delta(\varepsilon / d+\xi))(d+t \xi)<d$, which is contradiction. This implies that the $\lim _{n \longrightarrow \infty}\left\|u_{n}-T u_{n}\right\|=0$.

Now, we prove that $\left\|u_{n+1}-u_{n}\right\| \longrightarrow 0$. We have $\left\|u_{n+1}-u_{n}\right\| \leq\left(\alpha_{n} \beta_{n}+1\right)\left\|T u_{n}-u_{n}\right\|$.

Now, we define $b_{n}=\left(u_{n+1}-v\right) /\left(\left\|u_{n}-v\right\|\right)$, $v_{n}=\left(T v_{n}-v\right) /\left(\left\|u_{n}-v\right\|\right)$, and $u_{n}=\left(T u_{n}-v\right) /\left(\left\|u_{n}-v\right\|\right)$. One can note that $\left\|u_{n}\right\| \leq 1$. Now,

$$
\begin{aligned}
\left\|T v_{n}-v\right\| & =\left\|T v_{n}-T v\right\| \\
& \leq\left\|v_{n}-v\right\| \\
& =\left\|\left(1-\beta_{n}\right) u_{n}+\beta_{n} T u_{n}-v\right\| \\
& =\left\|\left(1-\beta_{n}\right) u_{n}-\left(1-\beta_{n}\right) v+\beta_{n}\left(T u_{n}-v\right)\right\| \\
& \leq\left(1-\beta_{n}\right)\left\|u_{n}-v\right\|+\beta_{n}\left\|T u_{n}-T v\right\| \\
& \leq\left(1-\beta_{n}\right)\left\|u_{n}-v\right\|+\beta_{n}\left\|u_{n}-v\right\| \\
& =\left\|u_{n}-v\right\| .
\end{aligned}
$$

Therefore, $\quad\left\|v_{n}\right\|=\left(\left\|T v_{n}-v\right\|\right) /\left(\left\|u_{n}-v\right\|\right) \leq\left(\left\|u_{n}-v\right\|\right) /$ $\left(\left\|u_{n}-v\right\|\right)=1$. From Agarwal's iteration, we obtain $u_{n+1}-v=\left(1-\alpha_{n}\right)\left(T u_{n}-v\right)+\alpha_{n}\left(T v_{n}-v\right)$. Dividing by $\left\|u_{n}-v\right\|$, we obtain

$$
\frac{u_{n+1}-v}{\left\|u_{n}-v\right\|}=\left(1-\alpha_{n}\right) \frac{\left(T u_{n}-v\right)}{\left\|u_{n}-v\right\|}+\alpha_{n} \frac{\left(T v_{n}-v\right)}{\left\|u_{n}-v\right\|} .
$$

Hence, $b_{n}=\left(1-\alpha_{n}\right) u_{n}+\alpha_{n} v_{n}$. Now, we show that $\left\|b_{n}\right\| \longrightarrow 1$. Now,

$$
\lim _{n \longrightarrow \infty}\left\|b_{n}\right\|=\lim _{n \longrightarrow \infty} \frac{\left\|u_{n+1}-v\right\|}{\left\|u_{n}-v\right\|}=\frac{d}{d}=1 .
$$

By Lemma 1, $\left\|u_{n}-v_{n}\right\| \longrightarrow 0$. This implies that $\left\|u_{n}-T u_{n}\right\| \longrightarrow 0$. Therefore, $\left\|u_{n+1}-u_{n}\right\| \longrightarrow 0$.

Since $T(E)$ is contained in a compact set, $\left\{T u_{n}\right\}$ has a subsequence $\left\{T u_{n_{k}}\right\}$ that converges to point $b \in H$. Also, $\left\{u_{n_{k}}\right\}$ and $\left\{u_{n_{k}+1}\right\}$ converge to $b$. This implies that $\left\{u_{n}\right\}$ converge to $b$. Then, $T u_{n} \longrightarrow b$. In particular, $T u_{n_{k}} \longrightarrow b$. Since $T$ is continuous, implies that $T u_{n_{k}} \longrightarrow T b$. Therefore, $T b=b$

Theorem 5 (see [28]). Let $H$ and $L$ be nonempty closed bounded convex subset of a UCBS. Let T: $H \cup L \longrightarrow H \cup L$ satisfy

(1) $T(H) \subseteq H$ and $T(L) \subseteq L$

(2) $\|T u-T v\| \leq\|u-v\|$ for all $u \in H, v \in L$

Let $u_{0} \in H$ and define $u_{n+1}=P^{n}\left(\left(1-\alpha_{n}\right) u_{n}+\alpha_{n} T v_{n}\right)$, where $\quad \alpha_{n} \in(\varepsilon, 1-\varepsilon), n=0,1,2, \ldots$ and $\varepsilon \in(0,1 / 2)$. 
Then, $\lim _{n \rightarrow \infty}\left\|u_{n}-T u_{n}\right\|=0$. Moreover, if $T(H)$ lies in a compact set, $\left\{u_{n}\right\}$ converges to a fixed point of $T$.

Assume that $H$ be a convex closed subset of a Hilbert space $X$. Then, for $u \in X, P_{H}(u)$ is the nearest to $u$ and element of $H$. Furthermore, $P_{H}$ is nonexpansive and distinguished by Kolmogorove's criterion:

$$
\left\langle u-P_{H}(u), P_{H}(u)-b\right\rangle \geq 0, \quad \text { for all } u \in X \text { and } b \in H \text {. }
$$

Assume that $H$ and $L$ are two convex closed subsets of $X$. Set

$$
P(u)=P_{H}\left(P_{L}(u)\right), \quad \text { for each } u \in X .
$$

Then, the sequences $\left\{P^{n}(u)\right\} \subset H$ and $\left\{P_{L}\left(P^{n}(u)\right)\right\} \subset L$. When $H$ and $L$ are closed, the convergence of these sequences were established by Von Neumann in [35]. The sequences $\left\{P^{n}(u)\right\}$ and $\left\{P_{L}\left(P^{n}(u)\right)\right\}$ are called Von Neumann sequences (sometimes called alternating projection algorithm for two sets).

Definition 2 (see [36]). Suppose $H$ and $L$ are two nonempty convex closed subsets of a Hilbert space $X$. Then, $(H, L)$ is called boundedly regular provided that, for every bounded subset $S$ of $X$ and for every $\varepsilon>0$ one can select a $\delta>0$ such that

$$
\max \{d(u, H), d(u, L-z)\} \leq \delta \Rightarrow d(u, L) \leq \varepsilon, \forall u \in X,
$$

where $z=P_{\overline{L-H}}(0)$ is the displacement vector from the set $H$ to set $L(z$ is the unique vector such that $\|z\|=d(H, L))$.

Theorem 6 (see [36]). Suppose $(H, L)$ is boundedly regular; then, the Von Neumann sequence converges in norm.

Theorem 7 (see [36]). Assume that one of the $H$ and $L$ is boundedly compact; then, $(H, L)$ is boundedly regular.

Lemma 2 (see [37]). Suppose that $H$ be a nonempty convex closed subset and $L$ be a nonempty closed subset of a UCBS. Assume that $\left\{u_{n}\right\}$ and $\left\{b_{n}\right\}$ be sequences in $H$ and $\left\{v_{n}\right\}$ be a sequence in $L$ such that

(i) $\left\|u_{n}-v_{n}\right\| \longrightarrow d(H, L)$

(ii) $\left\|b_{n}-v_{n}\right\| \longrightarrow d(H, L)$

Then, $\left\|u_{n}-b_{n}\right\|$ converges to 0 .

Corollary 1 (see [37]). Suppose $H$ be a nonempty closed convex subset and $L$ be a nonempty closed subset of a UCBS. Assume that $\left\{u_{n}\right\}$ be a sequence in $H$ and $v_{0} \in L$ such that $\left\|u_{n}-v_{0}\right\| \longrightarrow d(H, L)$. Then, $\left\{u_{n}\right\}$ converges to $P_{H}\left(v_{0}\right)$.
Proposition 2 (see [15]). Suppose $H$ and L be two closed and convex subset of a Hilbert space $X$. Then, $P_{L}(H) \subseteq L$, $P_{H}(L) \subseteq H$, and $\left\|P_{L} u-P_{H} v\right\| \leq\|u-v\|$ for each $u \in H$ and $v \in L$.

Lemma 3. Suppose $H$ and $L$ be two closed and convex subset of a Hilbert space $X$. Then, for each $u \in X$, we have

$$
\left\|P^{n+1}(u)-b\right\| \leq\left\|P^{n}(u)-b\right\|, \quad \text { for } b \in H_{0} \cup L_{0} .
$$

\section{Main Results}

Theorem 8. Suppose $H$ and $L$ be nonempty bounded closed convex subsets of a UCBS $X$ and assume that $T: H \cup L \longrightarrow H \cup L$ such that

(i) $T(H) \subseteq H$ and $T(L) \subseteq L$

(ii) $\|T u-T v\| \leq\|u-v\|$, for all $u \in H, v \in L$

Select $u_{0} \in H$ and set $v_{n}=\left(1-\beta_{n}\right) u_{n}+\beta_{n} T u_{n}$, $u_{n+1}=\left(1-\alpha_{n}\right) T u_{n}+\alpha_{n} T v_{n}$, where $\beta_{n}, \alpha_{n} \in(\varepsilon, 1-\varepsilon), n=$ $0,1,2, \ldots$ and $\varepsilon \in(0,1 / 2)$ and $\sum \alpha_{n} \beta_{n}<\infty$. Suppose $d\left(u_{n}, H_{0}\right) \longrightarrow 0$, then $\lim _{n \longrightarrow \infty}\left\|u_{n}-T u_{n}\right\|=0$. Moreover, if $T(H)$ lies in a compact set, then $\left\{u_{n}\right\}$ converges to a fixed point of $T$.

Proof. If $d(H, L)=0$, then $H_{0}=L_{0}=H \cap L$, and by Theorem 4 , we can establish the theorem from the fact that $T: H \cap L \longrightarrow H \cap L$ is nonexpansive. Let $d(H, L)>0$. By Theorem 2, there exists $v \in L_{0}$ such that $T v=v$. Now,

$$
\begin{aligned}
\left\|v_{n}-z\right\| & =\left\|\left(1-\beta_{n}\right) u_{n}+\beta_{n} T u_{n}-v\right\| \\
& \leq\left(1-\beta_{n}\right)\left\|u_{n}-v\right\|+\beta_{n}\left\|T u_{n}-T v\right\| \\
& \leq\left(1-\beta_{n}\right)\left\|u_{n}-v\right\|+\beta_{n}\left\|u_{n}-v\right\| \\
& =\left\|u_{n}-v\right\|,
\end{aligned}
$$

which implies that

$$
\begin{aligned}
\left\|u_{n+1}-v\right\| & =\left\|\left(1-\alpha_{n}\right) T u_{n}+\alpha_{n} T v_{n}-v\right\| \\
& \leq\left(1-\alpha_{n}\right)\left\|T u_{n}-v\right\|+\alpha_{n}\left\|T v_{n}-v\right\| \\
& \leq\left(1-\alpha_{n}\right)\left\|u_{n}-v\right\|+\alpha_{n}\left\|v_{n}-v\right\| \\
& \leq\left(1-\alpha_{n}\right)\left\|u_{n}-v\right\|+\alpha_{n}\left\|u_{n}-v\right\| \\
& =\left\|u_{n}-v\right\| .
\end{aligned}
$$

Hence, the sequence $\left\{\left\|u_{n}-v\right\|\right\}$ is nonincreasing. So, one can select a $d>0$ such that $\lim _{n \rightarrow \infty}\left\|u_{n}-v\right\|=d$. Assume that there is a subsequence $\left\{u_{n_{k}}\right\}$ of $\left\{u_{n}\right\}$ and an $\varepsilon>0$ such that $\left\|u_{n_{k}}-T u_{n_{k}}\right\| \geq \varepsilon>0$ for every $k$. 
However, the modulus of convexity $\delta$ of $X$ is continuous and increasing function, and we choose $\xi>0$ as small that $(1-c \delta(\varepsilon /(d+\xi)))(d+\xi)<d$, where $c>0$.
Now, we choose $k$, such that $\left\|u_{n_{k}}-v\right\| \leq d+\xi$. By Proposition 1, we have

$$
\begin{aligned}
& \left\|v-u_{n_{k}+1}\right\|=\left\|v-\left(\left(1-\alpha_{n_{k}}\right) T u_{n_{k}}+\alpha_{n_{k}} T v_{n_{k}}\right)\right\| \\
& =\left\|v-\left(\left(1-\alpha_{n_{k}}\right) T u_{n_{k}}+\alpha_{n_{k}} T\left(\left(1-\beta_{n_{k}}\right) u_{n_{k}}+\beta_{n_{k}} T u_{n_{k}}\right)\right)\right\| \\
& =\|\left(1-\alpha_{n_{k}}\right) v+\alpha_{n_{k}} v-\left(\left(1-\alpha_{n_{k}}\right) T u_{n_{k}}+\alpha_{n_{k}} T\left(\left(1-\beta_{n_{k}}\right) u_{n_{k}}\right.\right. \\
& \left.\left.+\beta_{n_{k}} T u_{n_{k}}\right)\right) \| \\
& \leq\left(1-\alpha_{n_{k}}\right)\left\|v-T u_{n_{k}}\right\|+\alpha_{n_{k}}\left\|v-T\left(\left(1-\beta_{n_{k}}\right) u_{n_{k}}+\beta_{n_{k}} T u_{n_{k}}\right)\right\| \\
& =\left(1-\alpha_{n_{k}}\right)\left\|T v-T u_{n_{k}}\right\|+\alpha_{n_{k}}\left\|T v-T\left(\left(1-\beta_{n_{k}}\right) u_{n_{k}}+\beta_{n_{k}} T u_{n_{k}}\right)\right\| \\
& \leq\left(1-\alpha_{n_{k}}\right)(d+\xi)+\alpha_{n_{k}}\left\|v-\left(\left(1-\beta_{n_{k}}\right) u_{n_{k}}+\beta_{n_{k}} T u_{n_{k}}\right)\right\| \\
& =\left(1-\alpha_{n_{k}}\right)(d+\xi)+\alpha_{n_{k}}\left\|\left(1-\beta_{n_{k}}\right)\left(v-u_{n_{k}}\right)+\beta_{n_{k}}\left(v-T u_{n_{k}}\right)\right\| \\
& \leq\left(1-\alpha_{n_{k}}\right)(d+\xi)+\alpha_{n_{k}}\left(1-2 \delta\left(\frac{\varepsilon}{d+\xi}\right) \min \left\{\beta_{n_{k}}, 1-\beta_{n_{k}}\right\}\right)(d+\xi) \\
& =\left(1-\alpha_{n_{k}}+\alpha_{n_{k}}-2 \alpha_{n_{k}} \delta\left(\frac{\varepsilon}{d+\xi}\right) \min \left\{\beta_{n_{k}}, 1-\beta_{n_{k}}\right\}\right)(d+\xi) \\
& =\left(1-2 \delta\left(\frac{\varepsilon}{d+\xi}\right) \min \left\{\alpha_{n_{k}} \beta_{n_{k}}, \alpha_{n_{k}}\left(1-\beta_{n_{k}}\right)\right\}\right)(d+\xi) .
\end{aligned}
$$

Since there exist $h>0$ such that $\left\|T v_{n}-v\right\|=\left\|T v_{n}-T v\right\|$ $2 \min \left\{\alpha_{n_{k}} \beta_{n_{k}}, \alpha_{n_{k}}\left(1-\beta_{n_{k}}\right)\right\} \geq h$,

$$
\begin{aligned}
& \left(1-2 \delta\left(\frac{\varepsilon}{d+\xi}\right) \min \left\{\alpha_{n_{k}} \beta_{n_{k}}, \alpha_{n_{k}}\left(1-\beta_{n_{k}}\right)\right\}\right)(d+\xi) \\
& \leq\left(1-h \delta\left(\frac{\varepsilon}{d+\xi}\right)\right)(d+\xi) .
\end{aligned}
$$

Suppose choosing very small $\xi>0$, we have $(1-h \delta(\varepsilon /(d+\xi)))(d+\xi)<d$, which is a contradiction. This implies that $\lim _{n \longrightarrow \infty}\left\|u_{n}-T u_{n}\right\|=0$.

Now, we prove that $\left\|u_{n+1}-u_{n}\right\| \longrightarrow 0$. We have $\left\|u_{n+1}-u_{n}\right\| \leq\left(\alpha_{n} \beta_{n}+1\right)\left\|T u_{n}-u_{n}\right\|$. Now, we define $b_{n}=\left(u_{n+1}-z\right) /\left(\left\|u_{n}-v\right\|\right), v_{n}=\left(T v_{n}-v\right) /\left(\left\|u_{n}-v\right\|\right)$, and $u_{n}=\left(T u_{n}-v\right) /\left(\left\|u_{n}-v\right\|\right)$. One can note that $\left\|u_{n}\right\| \leq 1$. Now,

$$
\begin{aligned}
& =\left\|\left(1-\beta_{n}\right) u_{n}-\left(1-\beta_{n}\right) v+\beta_{n}\left(T u_{n}-v\right)\right\| \\
& \leq\left(1-\beta_{n}\right)\left\|u_{n}-v\right\|+\beta_{n}\left\|T u_{n}-T v\right\| \\
& \leq\left(1-\beta_{n}\right)\left\|u_{n}-v\right\|+\beta_{n}\left\|u_{n}-v\right\| \\
& =\left\|u_{n}-v\right\| .
\end{aligned}
$$

Therefore, $\quad\left\|v_{n}\right\|=\left(\left\|T v_{n}-v\right\|\right) /\left(\left\|u_{n}-v\right\|\right) \leq\left(\left\|u_{n}-v\right\|\right) /$ $\left(\left\|u_{n}-v\right\|\right)=1$. From Agarwal's iteration, we obtain $u_{n+1}-v=\left(1-\alpha_{n}\right)\left(T u_{n}-v\right)+\alpha_{n}\left(T v_{n}-v\right)$. Dividing by $\left\|u_{n}-v\right\|$, we obtain 


$$
\frac{u_{n+1}-v}{\left\|u_{n}-v\right\|}=\left(1-\alpha_{n}\right) \frac{\left(T u_{n}-v\right)}{\left\|u_{n}-v\right\|}+\alpha_{n} \frac{\left(T v_{n}-v\right)}{\left\|u_{n}-v\right\|} .
$$

Then, $b_{n}=\left(1-\alpha_{n}\right) u_{n}+\alpha_{n} v_{n}$. Now, we prove that $\left\|b_{n}\right\| \longrightarrow 1$. Now,

$$
\lim _{n \longrightarrow \infty}\left\|b_{n}\right\|=\lim _{n \longrightarrow \infty} \frac{\left\|u_{n+1}-v\right\|}{\left\|u_{n}-v\right\|}=\frac{d}{d}=1 .
$$

By Lemma $1,\left\|u_{n}-v_{n}\right\| \longrightarrow 0$. This shows that $\left\|u_{n}-T u_{n}\right\| \longrightarrow 0$. Therefore, $\left\|u_{n+1}-u_{n}\right\| \longrightarrow 0$.

Since $T(H)$ is contained in a compact set, $\left\{T u_{n}\right\}$ has a subsequence $\left\{T u_{n_{k}}\right\}$ that converges to point $b \in H$. Also, $\left\{u_{n_{k}}\right\}$ and $\left\{u_{n_{k}+1}\right\}$ converge to $b$.

Since $d\left(u_{n}, H_{0}\right) \longrightarrow 0$, there exists $\left\{b_{n}\right\} \subseteq H_{0}$, such that $\left\|u_{n}-b_{n}\right\| \longrightarrow 0$. Therefore, $b_{n_{k}} \longrightarrow b$, which gives that $b \in H_{0}$.

Let $D=d(H, L)$ and choose $p \in L_{0}$ such that $\|b-p\|=D$.

We have $\quad\left\|u_{n_{k}}-p\right\| \longrightarrow\|b-p\|=D, \quad$ and $\left\|u_{n_{k}}-p\right\| \geq\left\|T u_{n_{k}}-T p\right\| \stackrel{n_{k}}{\longrightarrow}\|b-T p\|$. So, $\|b-T p\|=D$. By strict convexity of the norm, $T p=p$. It follows that $T b=b$.

Corollary 2. Suppose $H$ and $L$ are two nonempty bounded closed convex subsets of a UCBS $X$, and assume that $T: H \cup L \longrightarrow H \cup L$ is such that

(1) $T(H) \subseteq H$ and $T(L) \subseteq L$

(2) $\|T u-T v\| \leq\|u-v\|$ for all $u \in H, v \in L$

Choose $u_{0} \in H$ and set $v_{n}=\left(1-\beta_{n}\right) u_{n}+\beta_{n} T u_{n}, u_{n+1}=$ $\left(1-\alpha_{n}\right) T u_{n}+\alpha_{n} T v_{n}$, where $\beta_{n}, \alpha_{n} \in(\varepsilon, 1-\varepsilon), n=0,1,2, \ldots$ and $\varepsilon \in(0,1 / 2)$ and $\sum \alpha_{n} \beta_{n}<\infty$. Then, $\lim _{n \rightarrow \infty} \| u_{n}-$ $T u_{n} \|=0$. Moreover, if $T(H)$ contained in a compact set, then $\left\{u_{n}\right\}$ converges to a fixed point of $T$.

Corollary 3. Suppose $H$ and $L$ are two nonempty bounded closed convex subsets of a Hilbert space $X$, and assume that $T: H \cup L \longrightarrow H \cup L$ be a relatively nonexpansive mapping such that

(1) $T(H) \subseteq H$ and $T(L) \subseteq L$

(2) $\|T u-T v\| \leq\|u-v\|$ for all $u \in H, v \in L$

Choose $u_{0} \in H$ and set $v_{n}=\left(1-\beta_{n}\right) u_{n}+\beta_{n} T u_{n}, u_{n+1}=$ $P^{n}\left(\left(1-\alpha_{n}\right) T u_{n}+\alpha_{n} T v_{n}\right)$, where $\beta_{n}, \alpha_{n} \in(\varepsilon, 1-\varepsilon), n=$ $0,1,2, \ldots$ and $\varepsilon \in(0,1 / 2)$ and $\sum \alpha_{n} \beta_{n}<\infty$. Then, $\lim _{n \longrightarrow \infty}\left\|u_{n}-T u_{n}\right\|=0$. Moreover, if $T(H)$ is mapped into a compact subset of $L$, then $\left\{u_{n}\right\}$ converges to a fixed point of $T$.

Proof. One can note that $P^{n}\left(\left(1-\alpha_{n}\right) T u_{n}+\alpha_{n} T v_{n}\right)=$ $\left(1-\alpha_{n}\right) T u_{n}+\alpha_{n} T v_{n}$, and by Theorem 8 , the result follows.

Now, we present a new example of relatively nonexpansive mappings and prove that its Agarwal [32] iterative process is better than the Mann [29] and Ishikawa [31] iterative processes.

Example 1. Take $X=\mathbb{R}^{2}$,

$$
\begin{array}{r}
H=\{(u, 0):-4 \leq u \leq-3\}, \\
L=\left\{\left(u^{\prime}, 0\right): 3 \leq u^{\prime} \leq 4\right\} .
\end{array}
$$

Define

$$
\begin{gathered}
T: H \longrightarrow H \text { by } T(u, 0)=\left(\frac{u-4}{5}, 0\right), \\
T: L \longrightarrow L \text { by } T\left(u^{\prime}, 0\right)=\left(\frac{u^{\prime}+4}{5}, 0\right) .
\end{gathered}
$$

Let $(u, 0) \in H$ and $\left(u^{\prime}, 0\right) \in L$. Then,

$$
\begin{aligned}
\left\|T(u, 0)-T\left(u^{\prime}, 0\right)\right\| & =\left\|\left(\frac{u-4}{5}, 0\right)-\left(\frac{u^{\prime}+4}{5}, 0\right)\right\| \\
& =\left\|\left(\frac{u-u^{\prime}-8}{5}, 0\right)\right\| \\
& =\sqrt{\left(\frac{u-u^{\prime}-8}{5}\right)^{2}+0} \\
& \leq \sqrt{\left(u-u^{\prime}\right)^{2}} \\
& =\left\|(u, 0)-\left(u^{\prime}, 0\right)\right\| .
\end{aligned}
$$

From the above process, we get $T$ is relatively nonexpansive mapping. The iterative values for $u_{0}=-1.5$ are shown below in Table 1 and Figure 1.

Remark 1. From Table 1 and Figure 1, we see that Agarwal iterates converges faster to -1 than the Ishikawa and Mann iterates for the class of relatively nonexpansive mappings.

The stronger version for the approximation of fixed point by using Von Neumann sequences are follows.

Theorem 9. Let $H$ and $L$ be nonempty bounded closed convex subsets of a Hilbert space $X$ and suppose $T: H \cup L \longrightarrow H \cup L$ is such that

(1) $T(H) \subseteq H$ and $T(L) \subseteq L$

(2) $\|T u-T v\| \leq\|u-v\|$ for all $u \in H, v \in L$

Let $u_{0} \in H$ and define $v_{n}=\left(1-\beta_{n}\right) u_{n}+\beta_{n} T u_{n}, u_{n+1}=$ $P^{n}\left(\left(1-\alpha_{n}\right) T u_{n}+\alpha_{n} T v_{n}\right)$, where $\beta_{n}, \alpha_{n} \in(\varepsilon, 1-\varepsilon), n=$ $0,1,2, \ldots$ with restriction $\sum_{n \rightarrow \infty} \alpha_{n} \beta_{n}<\infty$ and $\varepsilon \in(0,1 / 2)$ and $\sum \alpha_{n} \beta_{n}<\infty$. Then, $\lim _{n \longrightarrow \infty}\left\|u_{n}-T u_{n}\right\|=0$. Moreover, if $T(H)$ is lies in a compact set and $\left\|u_{n}-T v_{n}\right\| \longrightarrow 0$, then $\left\{u_{n}\right\}$ converges to a fixed point of $T$. 
TABLE 1: Sequences generated by Agarwal, Ishikawa, and Mann iterative algorithms.

\begin{tabular}{lccc}
\hline & Agarwal & Ishikawa & Mann \\
\hline$u_{0}$ & -1.5 & -1.5 & -1.5 \\
$u_{1}$ & -1.028000072000000 & -1.068000072000000 & -1.100000400000000 \\
$u_{2}$ & -1.001568008064010 & -1.009248019584011 & -1.020000160000320 \\
$u_{3}$ & -1.000087808677378 & -1.001257731995140 & -1.004000048000192 \\
$u_{4}$ & -1.000004917298577 & -1.000800012800077 \\
$u_{5}$ & -1.000000275369428 & -1.0000171051732452 & -1.000160003200025 \\
$u_{6}$ & -1.000000015420727 & -1.000003163779543 & -1.000032000768007 \\
$u_{7}$ & -1.000000000863563 & -1.000000430274473 & -1.000006400179202 \\
$u_{8}$ & -1.000000000048359 & -1.000000058517390 & -1.000001280040961 \\
$u_{9}$ & -1.000000000002708 & -1.000000007958373 & -1.000000256009216 \\
$u_{10}$ & -1.000000000000151 & -1.000000001082346 & -1.000000051202048 \\
$u_{11}$ & -1.000000000000008 & -1.000000000147198 & -1.000000010240450 \\
$u_{12}$ & -1 & -1.000000000020019 & -1.000000002048098 \\
$u_{13}$ & -1 & -1.000000000002722 & -1.000000000409621 \\
$u_{14}$ & -1 & -1.000000000000370 & -1.000000000081924 \\
$u_{15}$ & - & -1.000000000000050 & -1.000000000016385 \\
$u_{16}$ & -1 & -1.000000000000007 & -1.000000000003277 \\
$u_{17}$ & - & -1.000000000000001 & -1.000000000000655 \\
$u_{18}$ & -1 & -1 & -1.000000000000131 \\
$u_{19}$ & -1 & -1 & -1.000000000000026 \\
$u_{20}$ & -1 & -1 & -1.000000000000005 \\
\hline
\end{tabular}

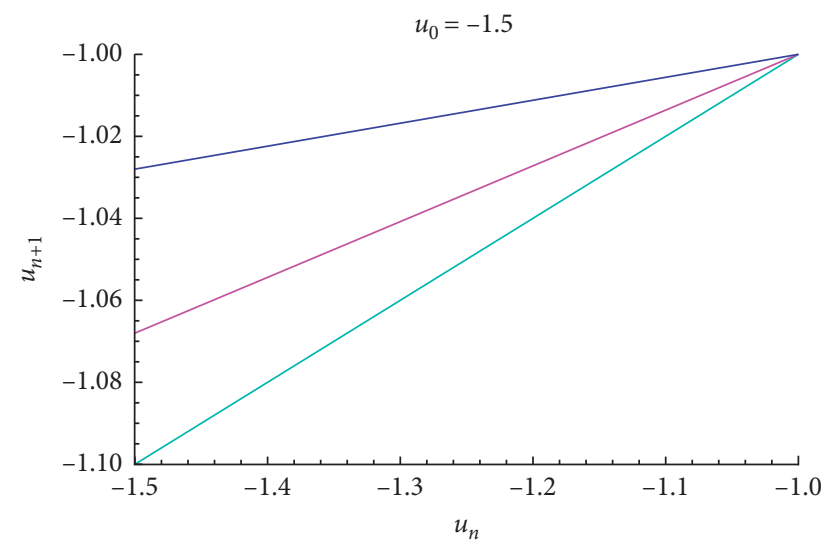

FIgURE 1: Convergence behavior of Agarwal (blue), Ishikawa (magenta), and Mann (cyan) iterates to the fixed point $v=-1$ of the mapping $T$.

Proof. If $d(H, L)=0$, then $H_{0}=L_{0}=H \cap L \quad$ and $T: H \cap L \longrightarrow H \cap L$ is nonexpansive with $u_{n+1}=P^{n}((1-$ $\left.\left.\alpha_{n}\right) T u_{n}+\alpha_{n} T\left(\left(1-\beta_{n}\right) u_{n}+\beta_{n} T u_{n}\right)\right)=\left(1-\alpha_{n}\right) T u_{n}+\alpha_{n} T$ $\left(\left(1-\beta_{n}\right) u_{n}+\beta_{n} T u_{n}\right)$, the usual Agarwal's iteration. So, let us take that $d(H, L)>0$. By Theorem 2, there exist $v \in L_{0}$ such that $T v=v$. Now,

$$
\begin{aligned}
\left\|v_{n}-v\right\| & =\left\|\left(1-\beta_{n}\right) u_{n}+\beta_{n} T u_{n}-v\right\| \\
& \leq\left(1-\beta_{n}\right)\left\|u_{n}-v\right\|+\beta_{n}\left\|T u_{n}-v\right\| \\
& \leq\left(1-\beta_{n}\right)\left\|u_{n}-v\right\|+\beta_{n}\left\|u_{n}-v\right\| \\
& =\left\|u_{n}-v\right\|,
\end{aligned}
$$

which implies that

$$
\begin{aligned}
\left\|u_{n+1}-v\right\| & =\left\|P^{n}\left(\left(1-\alpha_{n}\right) T u_{n}+\alpha_{n} T v_{n}\right)-v\right\| \\
& \leq\left\|\left(1-\alpha_{n}\right) T u_{n}+\alpha_{n} T v_{n}-v\right\| \\
& \leq\left(1-\alpha_{n}\right)\left\|T u_{n}-v\right\|+\alpha_{n}\left\|T v_{n}-v\right\| \\
& \leq\left(1-\alpha_{n}\right)\left\|T u_{n}-T v\right\|+\alpha_{n}\left\|T v_{n}-T v\right\| \\
& \leq\left(1-\alpha_{n}\right)\left\|u_{n}-v\right\|+\alpha_{n}\left\|v_{n}-v\right\| \\
& \leq\left(1-\alpha_{n}\right)\left\|u_{n}-v\right\|+\alpha_{n}\left\|u_{n}-v\right\| \\
& =\left\|u_{n}-v\right\| .
\end{aligned}
$$

Hence, the $e$ sequence $\left\{\left\|u_{n}-v\right\|\right\}$ is nonincreasing. So, one can choose some $d>0$ with $\lim _{n \longrightarrow \infty}\left\|u_{n}-v\right\|=d$. Assume that one can find a subsequence, namely, $\left\{u_{n_{k}}\right\}$ of $\left\{u_{n}\right\}$ and some positive $\varepsilon$ such that $\left\|u_{n_{k}}-T u_{n_{k}}\right\| \geq \varepsilon>0$ for every $k$. 
Since the modulus of convexity of $\delta$ of $X$ is continuous as well as increasing function, one may choose $\xi>0$ as small such that $(1-c \delta(\varepsilon /(d+\xi)))(d+\xi)<d$, where $c>0$.
Now, we select $k$, such that $\left\|u_{n_{k}}-v\right\| \leq d+\xi$. By Proposition 1 , we have

$$
\begin{aligned}
\left\|v-u_{n_{k}+1}\right\| & =\left\|v-P^{n_{k}}\left(\left(\left(1-\alpha_{n_{k}}\right) T u_{n_{k}}+\alpha_{n_{k}} T v_{n_{k}}\right)\right)\right\| \\
& \leq\left\|v-\left(\left(1-\alpha_{n_{k}}\right) T u_{n_{k}}+\alpha_{n_{k}} T v_{n_{k}}\right)\right\| \\
& =\left\|v-\left(\left(\left(1-\alpha_{n_{k}}\right) T u_{n_{k}}+\alpha_{n_{k}} T\left(\left(1-\beta_{n_{k}}\right) u_{n_{k}}+\beta_{n_{k}} T u_{n_{k}}\right)\right)\right)\right\| \\
& =\left\|\left(1-\alpha_{n_{k}}\right) v+\alpha_{n_{k}} v-\left(\left(1-\alpha_{n_{k}}\right) T u_{n_{k}}+\alpha_{n_{k}} T\left(\left(1-\beta_{n_{k}}\right) u_{n_{k}}+\beta_{n_{k}} T u_{n_{k}}\right)\right)\right\| \\
& \leq\left(1-\alpha_{n_{k}}\right)\left\|v-T u_{n_{k}}\right\|+\alpha_{n_{k}}\left\|v-T\left(\left(1-\beta_{n_{k}}\right) u_{n_{k}}+\beta_{n_{k}} T u_{n_{k}}\right)\right\| \\
& =\left(1-\alpha_{n_{k}}\right)\left\|T v-T u_{n_{k}}\right\|+\alpha_{n_{k}}\left\|T v-T\left(\left(1-\beta_{n_{k}}\right) u_{n_{k}}+\beta_{n_{k}} T u_{n_{k}}\right)\right\| \\
& \leq\left(1-\alpha_{n_{k}}\right)\left\|v-u_{n_{k}}\right\|+\alpha_{n_{k}}\left\|v-\left(\left(1-\beta_{n_{k}}\right) u_{n_{k}}+\beta_{n_{k}} T u_{n_{k}}\right)\right\| \\
& =\left(1-\alpha_{n_{k}}\right)(d+\xi)+\alpha_{n_{k}}\left\|\left(1-\beta_{n_{k}}\right)\left(v-u_{n_{k}}\right)+\beta_{n_{k}}\left(v-T u_{n_{k}}\right)\right\| \\
& \leq\left(1-\alpha_{n_{k}}\right)(d+\xi)+\alpha_{n_{k}}\left(\left(1-2 \delta\left(\frac{\varepsilon}{d+\xi}\right) \min \left\{\beta_{n_{k}}, 1-\beta_{n_{k}}\right\}\right) d+\xi\right) \\
& =\left(1-\alpha_{n_{k}}+\alpha_{n_{k}}-2 \alpha_{n_{k}} \delta\left(\frac{\varepsilon}{d+\xi}\right) \min \left\{\beta_{n_{k}}, 1-\beta_{n_{k}}\right\}\right)(d+\xi) \\
& \left(1-2 \delta\left(\frac{\varepsilon}{d+\xi}\right) \min \left\{\alpha_{n_{k}} \beta_{n_{k}}, \alpha_{n_{k}}\left(1-\beta_{n_{k}}\right)\right\}\right)(d+\xi) .
\end{aligned}
$$

Since there exist $h>0 \quad$ such that $\quad\left\|u_{n_{k+1}}-u_{n_{k}}\right\|=\left\|P^{n_{k}}\left(\left(1-\alpha_{n_{k}}\right) T u_{n_{k}}+\alpha_{n_{k}} T v_{n_{k}}\right)-u_{n_{k}}\right\|$

$2 \min \left\{\alpha_{n_{k}} \beta_{n_{k}}, \alpha_{n_{k}}\left(1-\beta_{n_{k}}\right)\right\} \geq h$ :

$$
\begin{aligned}
& \left(1-2 \delta\left(\frac{\varepsilon}{d+\xi}\right) \min \left\{\alpha_{n_{k}} \beta_{n_{k}}, \alpha_{n_{k}}\left(1-\beta_{n_{k}}\right)\right\}\right)(d+\xi) \\
& \leq\left(1-h \delta\left(\frac{\varepsilon}{d+\xi}\right)\right)(d+\xi) .
\end{aligned}
$$

If we select a small $\xi>0$, then $(1-h \delta(\varepsilon / d+\xi))(d+\xi)<d$ which is clearly a contradiction. This implies that $\lim _{n \longrightarrow \infty}\left\|u_{n}-T u_{n}\right\|=0$

Since the set $T(H)$ is contained in a compact set, so the sequence $\left\{T u_{n}\right\}$ has a subsequence $\left\{T u_{n_{k}}\right\}$ such that it converges to a some point $z_{0} \in H$. Also, $\left\{u_{n_{k}}\right\}$ converge to $z_{0}$. From the given sequence, one has

$$
\begin{aligned}
& \leq\left\|\left(1-\alpha_{n_{k}}\right) T u_{n_{k}}+\alpha_{n_{k}} T v_{n_{k}}-u_{n_{k}}\right\| \\
& =\left\|T u_{n_{k}}-\alpha_{n_{k}} T u_{n_{k}}+\alpha_{n_{k}} T v_{n_{n_{k}}}-u_{n_{k}}\right\| \\
& \leq \alpha_{n_{k}}\left\|T u_{n_{k}}-T v_{n_{k}}\right\|+\left\|T u_{n_{k}}-u_{n_{k}}\right\| \\
& \leq \alpha_{n_{k}}\left\|v_{n_{k}}-u_{n_{k}}\right\|+\left\|T u_{n_{k}}-u_{n_{k}}\right\| \\
& =\alpha_{n_{k}}\left\|\left(1-\beta_{n}\right) u_{n_{k}}+\beta_{n} T u_{n_{k}}-u_{n_{k}}\right\|+\left\|T u_{n_{k}}-u_{n_{k}}\right\| \\
& =\alpha_{n_{k}} \beta_{n_{k}}\left\|T u_{n_{k}}-u_{n_{k}}\right\|+\left\|T u_{n_{k}}-u_{n_{k}}\right\| \\
& =\left(\alpha_{n_{k}} \beta_{n_{k}}+1\right)\left\|T u_{n_{k}}-u_{n_{k}}\right\| \| .
\end{aligned}
$$

Since $\left\|T u_{n_{k}}-u_{n_{k}}\right\| \longrightarrow 0$ which implies that $\left\|u_{n_{k+1}}-u_{n_{k}}\right\| \longrightarrow 0$. Therefore, $u_{n_{k+1}} \longrightarrow z_{0}$, which implies that $u_{n} \longrightarrow z_{0}$. Also, we have $T v_{n_{k}} \longrightarrow z_{0}$ as $k \longrightarrow \infty$. 
Now, $\left\|T u_{n_{k}}-T\left(P_{L}\left(z_{0}\right)\right)\right\| \leq\left\|u_{n_{k}}-P_{L}\left(z_{0}\right)\right\|$, which gives that $\left\|z_{0}-T\left(P_{L}\left(z_{0}\right)\right)\right\| \leq\left\|z_{0}-P_{L}\left(z_{0}\right)\right\| . \quad$ Therefore, $T\left(P_{L}\left(z_{0}\right)\right)=P_{L}\left(z_{0}\right)$.

Also, $\quad\left\|T\left(P\left(z_{0}\right)\right)-P_{L}\left(z_{0}\right)\right\|=\left\|T\left(P\left(z_{0}\right)\right)-T\left(P_{L}\left(z_{0}\right)\right)\right\| \leq$ $\left\|P\left(z_{0}\right)-P_{L}\left(z_{0}\right)\right\|$. So, $T\left(P\left(z_{0}\right)\right)=P\left(z_{0}\right)$

Now, $\quad\left\|T\left(P_{L}\left(P\left(z_{0}\right)\right)\right)-P\left(z_{0}\right)\right\|=\| T\left(P_{L}\left(P\left(z_{0}\right)\right)\right)-$ $T\left(P\left(z_{0}\right)\right)\|\leq\| P_{L}\left(P\left(z_{0}\right)\right)-P\left(z_{0}\right) \|$. Thus, $T\left(P_{L}\left(P\left(z_{0}\right)\right)\right)=$ $P_{L}\left(P\left(z_{0}\right)\right)$.

For any $n, T\left(P^{n}\left(z_{0}\right)\right)=P^{n}\left(z_{0}\right)$ and $T\left(P_{L}\left(P^{n}\left(z_{0}\right)\right)\right)=$ $P_{L}\left(P^{n}\left(z_{0}\right)\right)$. By Theorem 6 , for each $u \in H$, the sequence $\left\{P^{n}(u)\right\}$ converges to some $w(u) \in H_{0}$. Now,

$$
\begin{aligned}
\left\|T\left(w\left(z_{0}\right)\right)-P_{L}\left(w\left(z_{0}\right)\right)\right\| & \leq \lim _{n \longrightarrow \infty}\left\|T\left(w\left(z_{0}\right)\right)-P_{L}\left(P^{n}\left(z_{0}\right)\right)\right\| \\
& =\lim _{n \longrightarrow \infty}\left\|T\left(w\left(z_{0}\right)\right)-T\left(P_{L}\left(P^{n}\left(z_{0}\right)\right)\right)\right\| \\
& \leq \lim _{n \longrightarrow \infty}\left\|w\left(z_{0}\right)-P_{L}\left(P^{n}\left(z_{0}\right)\right)\right\| \\
& =\left\|w\left(z_{0}\right)-P_{L}\left(w\left(z_{0}\right)\right)\right\| .
\end{aligned}
$$

So, $\left\|T\left(w\left(z_{0}\right)\right)-P_{L}\left(w\left(z_{0}\right)\right)\right\| \leq\left\|w\left(z_{0}\right)-P_{L}\left(w\left(z_{0}\right)\right)\right\|$.

Therefore, $\quad T\left(w\left(z_{0}\right)\right)=w\left(z_{0}\right)$, and similarly $T\left(P_{L}\left(w\left(z_{0}\right)\right)\right)=P_{L}\left(w\left(z_{0}\right)\right)$.

Now, we define $g_{n}: H \longrightarrow \mathbb{R}$ by $g_{n}(u)=\left\|P^{n}(u)-w(u)\right\|$.

Since $\quad\|w(u)-w(v)\|=\lim _{n \longrightarrow \infty}\left\|P^{n}(u)-P^{n}(v)\right\| \leq$ $\|u-v\|$, then we conclude that $w$ is continuous. Therefore, $g_{n}(u)$ is continuous and converges pointwise to zero. Since $w(u) \in H_{0}$, by Lemma 3, we obtain $g_{n+1} \leq g_{n}$. Therefore, $g_{n}$ converges uniformly on the compact set:

$$
S=\left\{\left(1-\alpha_{n_{k}}\right) T u_{n_{k}}+\alpha_{n_{k}} T v_{n_{k}}\right\} \cup\left\{z_{0}\right\} .
$$

Therefore,

$$
\lim _{n \longrightarrow \infty}\left\|P^{n_{k}}\left(\left(1-\alpha_{n_{k}}\right) T u_{n_{k}}+\alpha_{n_{k}} T v_{n_{k}}\right)-w\left(\left(1-\alpha_{n_{k}}\right) T u_{n_{k}}+\alpha_{n_{k}} T v_{n_{k}}\right)\right\|=0
$$

Since $w\left(\left(1-\alpha_{n_{k}}\right) T u_{n_{k}}+\alpha_{n_{k}} T v_{n_{k}}\right) \longrightarrow w\left(z_{0}\right)$, we get $u_{n_{k+1}} \longrightarrow w\left(z_{0}\right)$, which gives that $w\left(z_{0}\right)=z_{0}$. Therefore, $T z_{0}=T\left(w\left(z_{0}\right)\right)=w\left(z_{0}\right)=z_{0}$, which completes the proof.

Suppose $X$ is a Hilbert space and assume that $T$ be as in Theorem 1. Consider $P_{H} T: H \longrightarrow H$ and $P_{L} T: L \longrightarrow L$.

From Proposition 2, $\left\|P_{H} T(u)-P_{L} T(v)\right\| \leq\|u-v\|$ for $u \in H$ and $v \in L$, by Theorems 8 and 9 , we give the following results on convergence of best proximity points.

Corollary 4. Suppose $H$ and L are two nonempty bounded closed convex subsets of a Hilbert space X. Assume that T be as in Theorem 1. If T $(H)$ is mapped into a compact subset of $L$, then for every $u_{0} \in H_{0}$ the sequence generated by by $u_{n+1}=$ $\left(1-\alpha_{n}\right) T u_{n}+\alpha_{n} P_{H}\left(T\left(\left(1-\beta_{n}\right) u_{n}+\beta_{n} P_{H} T u_{n}\right)\right)$ converges to $u$ in $H_{0}$ such that $\|u-T u\|=d(H, L)$

Corollary 5. Suppose $H$ and $L$ are two nonempty bounded closed convex subsets of a Hilbert space X. Assume that $T$ be as in Theorem 1. If T $(H)$ is mapped into a compact subset of $L$, then for any $u_{0} \in H_{0}$ the sequence defined by $u_{n+1}=(1-$ $\left.\alpha_{n}\right) T u_{n}+\alpha_{n} P_{H}\left(T\left(\left(1-\beta_{n}\right) u_{n}+\beta_{n} P_{H} T u_{n}\right)\right)$ converges to $u$ in $H_{0}$ such that $\|u-T u\|=d(H, L)$ provided $d\left(u_{n}, H_{0}\right) \longrightarrow 0$.

Corollary 6. Suppose $H$ and $L$ are two nonempty bounded closed convex subsets of a Hilbert space X. Assume that $T$ be as in Theorem 1. If T $(H)$ is mapped into a compact subset of $L$, then for every $u_{0} \in H_{0}$ the sequence generated by $u_{n+1}=$ $P^{n}\left(\left(1-\alpha_{n}\right) T u_{n}+\alpha_{n} P_{H}\left(T\left(\left(1-\beta_{n}\right) u_{n}+\beta_{n} P_{H} T u_{n}\right)\right)\right)$ converges to $u$ in $H_{0}$ such that $\|u-T u\|=d(H, L)$

Proof. The result follows by Corollary 4.
Corollary 7. Suppose $H$ and $L$ are two nonempty bounded closed convex subsets of a Hilbert space X. Assume that $T$ be as in Theorem 1. Choose $u_{0} \in H$ and set $v_{n}=\left(1-\beta_{n}\right) u_{n}+\beta_{n} T u_{n}, u_{n+1}=P^{n}\left(\left(1-\alpha_{n}\right) T u_{n}+\alpha_{n} T v_{n}\right)$, where $\beta_{n}, \alpha_{n} \in(\varepsilon, 1-\varepsilon), n=0,1,2, \ldots$ and $\varepsilon \in(0,1 / 2)$ and $\sum \alpha_{n} \beta_{n}<\infty$. If $T(H)$ is mapped into a compact subset of $L$ and $\left\|u_{n}-P_{H} T v_{n}\right\| \longrightarrow 0$, then $\left\{u_{n}\right\}$ converges to $u$ in $H_{0}$ such that $\|u-T u\|=d(H, L)$.

Proof. The result follows by Theorem 9.

\section{Conclusions}

In this article, we have used the Agarwal iterative process for finding fixed points and best proximity points of relatively nonexpansive mappings. Using the Von Neumann sequence, we have established the convergence result in a Hilbert space framework. We have offered a new example of relatively nonexpansive mapping and proved that its Agarwal iterative process is more efficient than the Mann and Ishikawa iterative processes.

\section{Data Availability}

No data were used to support this study.

\section{Conflicts of Interest}

The authors declare that they have no conflicts of interest.

\section{Authors' Contributions}

All authors contributed equally and significantly in writing this article. All authors read and approved the final manuscript. 


\section{Acknowledgments}

The authors are grateful to the Spanish Government for Grant RTI2018-094336-B-I00 (MCIU/AEI/FEDER, UE) and Basque Government for Grant IT1207-19.

\section{References}

[1] W. A. Kirk, "A fixed point theorem for mappings which do not Increase Distances," The American Mathematical Monthly, vol. 72, no. 9, pp. 1004-1006, 1965.

[2] F. E. Browder, "Nonexpansive nonlinear operators in a Banach space," Proceedings of the National Academy of Sciences, vol. 54, no. 4, pp. 1041-1044, 1965.

[3] D. Göhde, "Zum Prinzip der Kontraktiven Abbildung," Mathematische Nachrichten, vol. 30, no. 3-4, pp. 251-258, 1965.

[4] K. Goebel and W. A. Kirk, "A fixed point theorem for asymptotically nonexpansive mappings," Proceedings of the American Mathematical Society, vol. 35, no. 1, p. 171, 1972.

[5] K. Aoyama and F. Kohsaka, "Fixed point theorem for -nonexpansive mappings in Banach spaces," Nonlinear Analysis: Theory, Methods \& Applications, vol. 74, no. 13, pp. 4387-4391, 2011.

[6] J. S. Bae, "Fixed point theorems of generalized nonexpansive mappings," Journal of the Korean Mathematical Society, vol. 21, no. 2, pp. 233-248, 1984.

[7] J. Bogin, "A generalization of a fixed point theorem of Goebel, Kirk and Shimi," Canadian Mathematical Bulletin, vol. 19, no. 1, pp. 7-12, 1976.

[8] K. Goebel, W. A. Kirk, and T. N. Shimi, "A fixed point theorem in uniformly convex spaces," Bollettino Della Unione Matematica Italiana, vol. 7, pp. 67-75, 1973.

[9] E. Llorens Fuster and E. Moreno Gálvez, "The Fixed Point Theory for some generalized nonexpansive mappings," $A b$ stract and Applied Analysis, vol. 2011, Article ID 435686, 15 pages, 2011.

[10] T. Suzuki, "Fixed point theorems and convergence theorems for some generalized nonexpansive mappings," Journal of Mathematical Analysis and Applications, vol. 340, no. 2, pp. 1088-1095, 2008.

[11] R. Pant and R. Shukla, "Approximating fixed points of generalized $\alpha$-nonexpansive mappings in Banach spaces," Numerical Functional Analysis and Optimization, vol. 38, no. 2, pp. 248-266, 2017.

[12] J. García-Falset, E. Llorens-Fuster, and T. Suzuki, "Fixed point theory for a class of generalized nonexpansive mappings," Journal of Mathematical Analysis and Applications, vol. 375, no. 1, pp. 185-195, 2011.

[13] B. Patir, N. Goswami, and V. N. Mishra, "Some results on fixed point theory for a class of generalized nonexpansive mappings," Fixed Point Theory and Applications, vol. 19, 2018.

[14] E. Karapinar and K. Tas, "Generalized (C)-conditions and related fixed point theorems," Computers and Mathematics with Applications, vol. 61, pp. 3370-3380, 2011.

[15] A. A. Eldred, W. A. Kirk, and P. Veeramani, "Proximal normal structure and relatively nonexpansive mappings," Studia Mathematica, vol. 171, no. 3, pp. 283-293, 2005.

[16] H. Ahmad, "Variational iteration method with an auxiliary parameter for solving differential equations of the fifth order," Nonlinear Science Letters A, vol. 9, no. 1, pp. 27-35, 2018.

[17] H. Ahmad, A. R. Seadawy, and T. A. Khan, "Numerical solution of Korteweg-de Vries-Burgers equation by the modified variational iteration algorithm-II arising in shallow water waves," vol. 95, no. 4, 2020.

[18] H. Ahmad, T. A. Khan, P. S. Stanimirovic, and I. Ahmad, "Modified variational iteration technique for the numerical solution of fifth order KdV type equations," Journal of Applied and Computational Mechanics, vol. 6, pp. 1220-1227, 2020.

[19] M. Nadeem, F. Li, and H. Ahmad, "Modified Laplace variational iteration method for solving fourth-order parabolic partial differential equation with variable coefficients," Computers \& Mathematics with Applications, vol. 78, no. 6, pp. 2052-2062, 2019.

[20] H. Ahmad, T. A. Khan, and S.-W. Yao, "An efficient approach for the numerical solution of fifth-order KdV equations," Open Mathematics, vol. 18, no. 1, pp. 738-748, 2020.

[21] K. Ullah, F. Ayaz, and J. Ahmad, "Some convergence results of $\mathrm{M}$ iterative process in Banach spaces," Asian-European Journal of Mathematics, Article ID 2150017, 2019.

[22] K. Ullah, J. Ahmad, and M. D. L. Sen, "On generalized nonexpansive maps in Banach spaces," Computation, vol. 8, no. 3 , p. $61,2020$.

[23] T. Abdeljawad, K. Ullah, J. Ahmad, and N. Mlaiki, "Iterative approximations for a class of generalized nonexpansive operators in Banach spaces," Discrete Dynamics in Nature and Society, vol. 2020, Article ID 4627260, 6 pages, 2020.

[24] K. Ullah, M. S. U. Khan, N. Muhammad, and J. Ahmad, "Approximation of endpoints for multivalued nonexpansive mappings in geodesic spaces," Asian-European Journal of Mathematics, vol. 13, no. 8, Article ID 2050141, 2020.

[25] K. Ullah, J. Ahmad, and N. Muhammad, "Approximation of endpoints for multi-valued mappings in metric spaces," Journal of Linear and Toplogical Algebra, vol. 9, no. 2, pp. 129-137, 2020.

[26] T. Abdeljawad, K. Ullah, J. Ahmad, and N. Mlaiki, "Iterative approximation of endpoints for multivalued mappings in Banach spaces," Journal of Function Spaces, vol. 2020, Article ID 2179059, 5 pages, 2020.

[27] K. Ullah, J. Ahmad, M. Arshad, M. de la Sen, and M. S. U. Khan, "Approximating stationary points of multivalued generalized nonexpansive mappings in metric spaces," Advances in Mathematical Physics, vol. 2020, Article ID 9086078, 6 pages, 2020.

[28] A. A. Eldred and A. Praveen, "Convergence of Mann's iteration for relatively nonexpansive mappings," Fixed Point Theory, vol. 18, no. 2, pp. 1-9, 2017.

[29] W. R. Mann, "Mean value methods in iteration," Proceedings of the American Mathematical Society, vol. 4, no. 3, pp. 506-510, 1953.

[30] R. Gopi and V. Pragadeeswarar, "Convergence of the Ishikawa iteration process for relatively non expansive mappings," 2019, http://arxiv.org/abs/1910.05541.

[31] S. Ishikawa, "Fixed points by a new iteration method," Proceedings of the American Mathematical Society, vol. 44, no. 1, p. 147, 1974.

[32] R. P. Agarwal, D. O’Regan, and D. R. Sahu, "Iterative construction of fixed points of nearly asymptotically nonexpansive mappings," Search Results, vol. 8, no. 1, pp. 61-79, 2007.

[33] C. Chidume, Some Geometric Properties of Banach Spaces, Springer, London, UK, 2009.

[34] W. G. Dotson, "On the Mann iterative process," Transactions of the American Mathematical Society, vol. 149, no. 1, p. 65, 1970.

[35] J. Von Neumann, Functional Operators: Measures and Integrals, Princeton University Press, Princeton, NJ, USA, 1950. 
[36] H. K. Bauschke and J. M. Borwien, "On the convergence of von Neumann's alternating projection algorithm for two sets," Set-Valued Anal.vol. 1, pp. 283-293, 1993.

[37] A. A. Eldred and P. Veeramani, "Existence and convergence of best proximity points," Journal of Mathematical Analysis and Applications, vol. 323, no. 2, pp. 1001-1006, 2006. 